\title{
el mono-raíl elemento auxiliar en la construcción
}

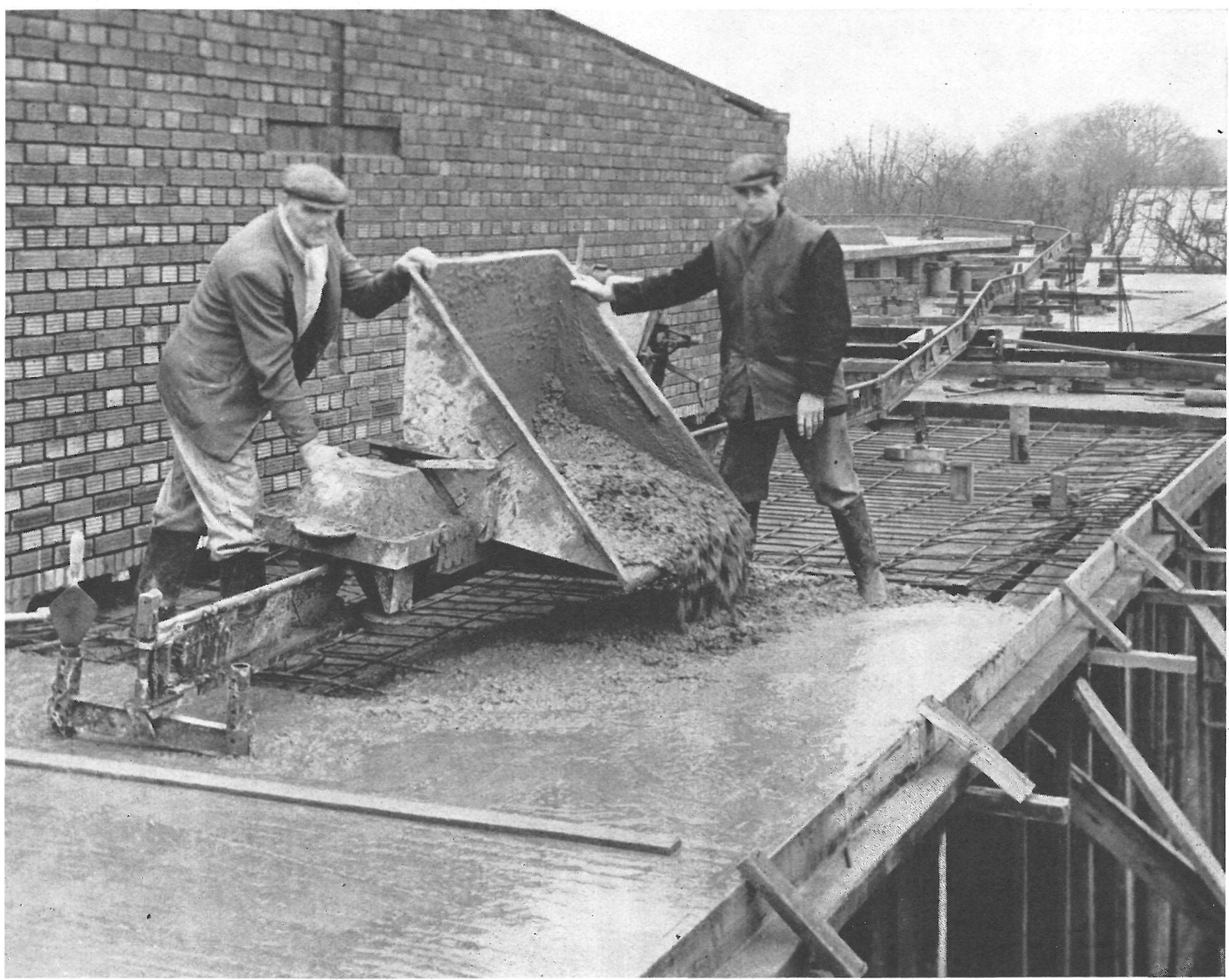

Los múltiples transportes de régimen interior de la propia obra, con sus distintas modalidades y casos particulares, han constituído siempre un problema delicado, al que ha sido necesario darle la importancia y amplitud que merece, puesto que de su buena y juiciosa solución depende en gran parte los precios unitarios de las distintas partes en que se puede despiezar la obra.

En este problema heterogéneo de transportes, no sólo ha de considerarse el volumen o cantidad -factores ambos de particular importancia-, sino las características intrínsecas del propio material que se ha de transportar. Así, pues, las condiciones que exige el transporte de elementos para el entramado de andamios no es el mismo que si se han de transportar las tierras o escombros procedentes de un vaciado o limpieza. Por tanto, la facilidad que se pueda ofrecer para cambiar las cajas de las vagonetas por mesillas de forma particular en cada caso, constituye una ventaja indudablemente apreciable.

Los caminos, rampas o plataformas de apoyo para los vehículos que han de realizar el transporte en obra tienen una decidida influencia en el resultado final. El transporte por mono-raíl necesita una vía constituída por un simple carril, cuyos apoyos son discontinuos, es decir, que basta soportar el carril en los puntos más indicados del trazado que ha de servir de base del transporte. Esta condición permite mayor amplitud en la elección de los lugares de apoyo que si se tratase de una vía continuamente apoyada.

Las paradas del vehículo automotor se pueden obtener por un dispositivo especial colocado en el carril, y, como el motor funciona sin necesidad de conductor, las economias de mano de obra que proporciona este sistema de transporte no son despreciables. 
La sencillez y ligereza del carril y sus soportes, así como el empleo de carriles de tipo curvo, constituyen un conjunto de características apropiadas para una fácil adaptación del carril al trazado, tanto en un plano como en altimetría.

\section{El mono-rail}

La unidad básica móvil de tracción es el vehículo automotor. Este vehículo está constituído por un bastidor, provisto, en general, de un tren de ruedas motrices y otro de ruedas libres. Como la base de apoyo sobre el carril es muy pequeña, se han previsto dos juegos de estabilizadores: uno en cada extremidad del bastidor. El elemento de cada juego de estabilizadores está formado por un eje vertical en cuya extremidad inferior lleva una rueda libre que gira al apoyarse contra el patín del raíl. Sobre el bastidor, en una extremidad, va montado un motor de tres caballos y los mecanismos correspondientes de transmisión y funcionamiento; en la parte central del bastidor se ha montado la caja basculante a los dos lados de la vía.

El bastidor puede transformarse fácilmente para acoplarle una mesilla o plataforma en lugar de la caja o recipiente normal.

La capacidad de carga de un vagón automotor es de unos $640 \mathrm{~kg}$, y su velocidad, de unos $100 \mathrm{~m}$ por minuto en horizontal. Puede subir rampas de hasta $1 / 12$ de pendiente.

Con estos automotores se pueden formar trenes de dos y más unidades, según los casos y circunstancias, para lo cual se fabrican vagones bascu- lantes de capacidad algo mayor que la de los automotores.

\section{La via y accesorios}

En este sistema de transporte se pueden emplear distintas disposiciones de trazado, pues éste es una consecuencia de la posición relativa de los centros de abastecimiento y entrega. Con objeto de lograr una rotación continua se han previsto cambios de dirección o agujas, que permiten la formación de apartaderos, vías muertas y bucles.

Los soportes de apoyo del carril pueden ser de varios tipos, pues dependen de la altura sobre el suelo que se ha de dar al carril. En general hay dos tipos: uno para apoyar directamente sobre la obra o terreno y otro para alturas de hasta $1,80 \mathrm{~m}$.

Los carriles que forman la vía se acopian sin necesidad de tornillos o bridas, lo que constituye una gran facilidad para el montaje de la vía. Los trozos de carril tienen $3,60 \mathrm{~m}$ de longitud; su cabeza está formada por un redondo de acero, y el patín, por un fleje. Estas dos partes se unen entre sí por medio de una chapa o celosía que constituye el cuerpo o alma del carril.

Los carriles curvos, de $1,80 \mathrm{~m}$ de longitud, tienen $3,60 \mathrm{~m}$ de radio, lo que permite formar curvas de $90^{\circ}$ con tres trozos curvos consecutivos.

Para poder formar vias muertas, derivaciones o lazos completos, según convenga al tipo general del trazado, estaciones de carga o de basculación, se han previsto agujas de cambio de vía de fácil manejo e instalación.

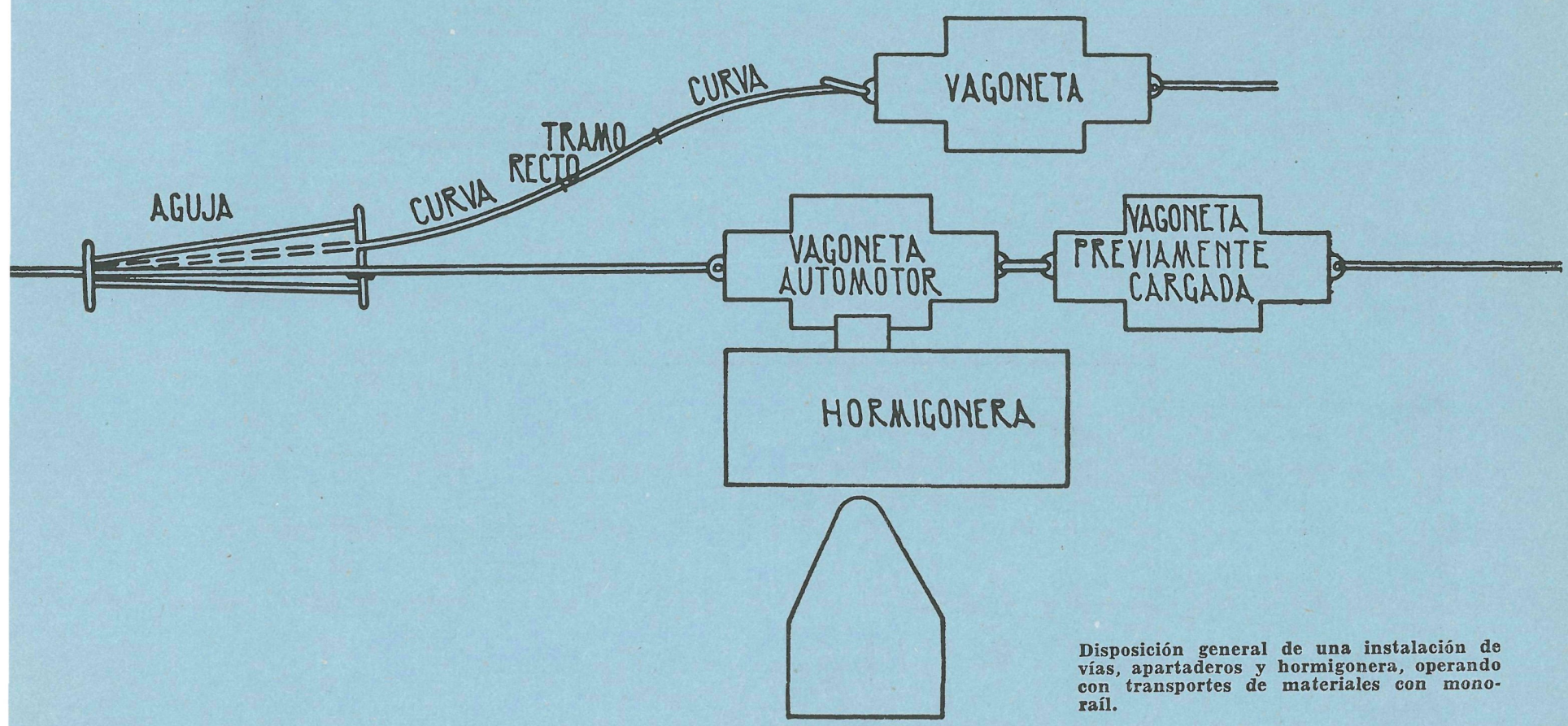


Además del tipo normal de vehículo automotor, se han fabricado unas vagonetas, también basculantes, que pueden engancharse al vagón automotor de cabeza para formar un tren de dos o más unidades, de acuerdo con la potencia, carga y características del trazado. Para facilitar las operaciones de carga o descarga de estos vagones, cuando se trata de llevarlos de una a otra obra, la casa inglesa Road Machines (Drayton) Ltd., constructora y propietaria de múltiples patentes de este tipo de maquinaria en distintos países, ha fabricado un chasis especial, que, provisto de un tren de ruedas neumáticas, permite que un solo operario pueda trasladar fácilmente estas vagonetas.

Sección transversal de una vagoneta auto motor.

Sección longitudinal de una vagoneta auto. motor, empleada en los transportes por mon

Aguja para el cambio de vía del mono-raíl.

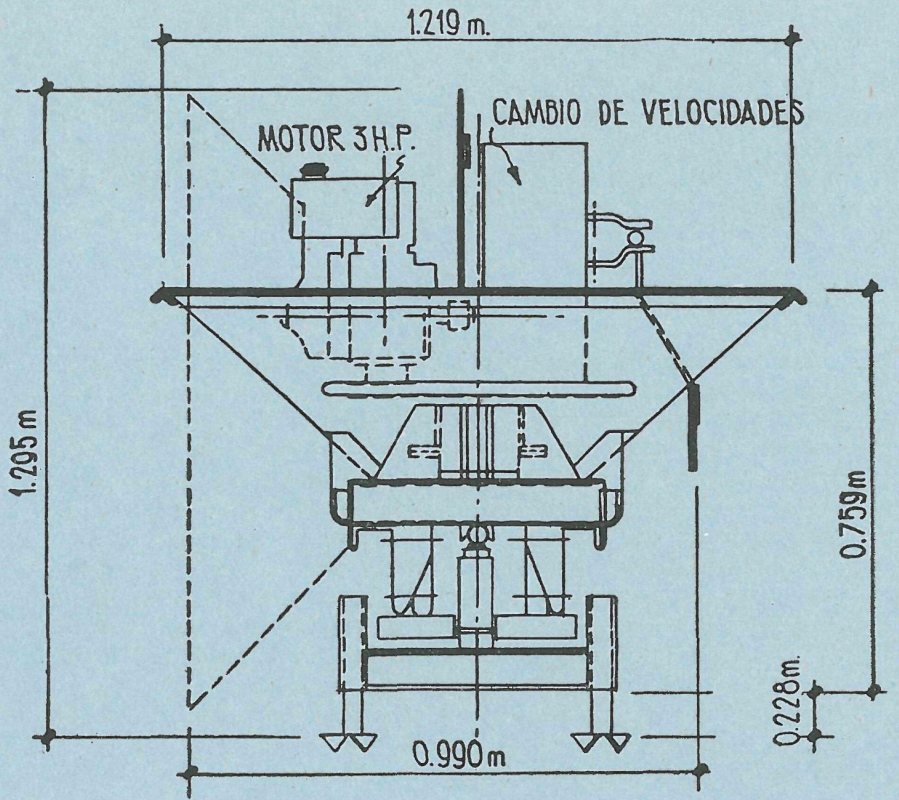

$2.43 \mathrm{~m}$

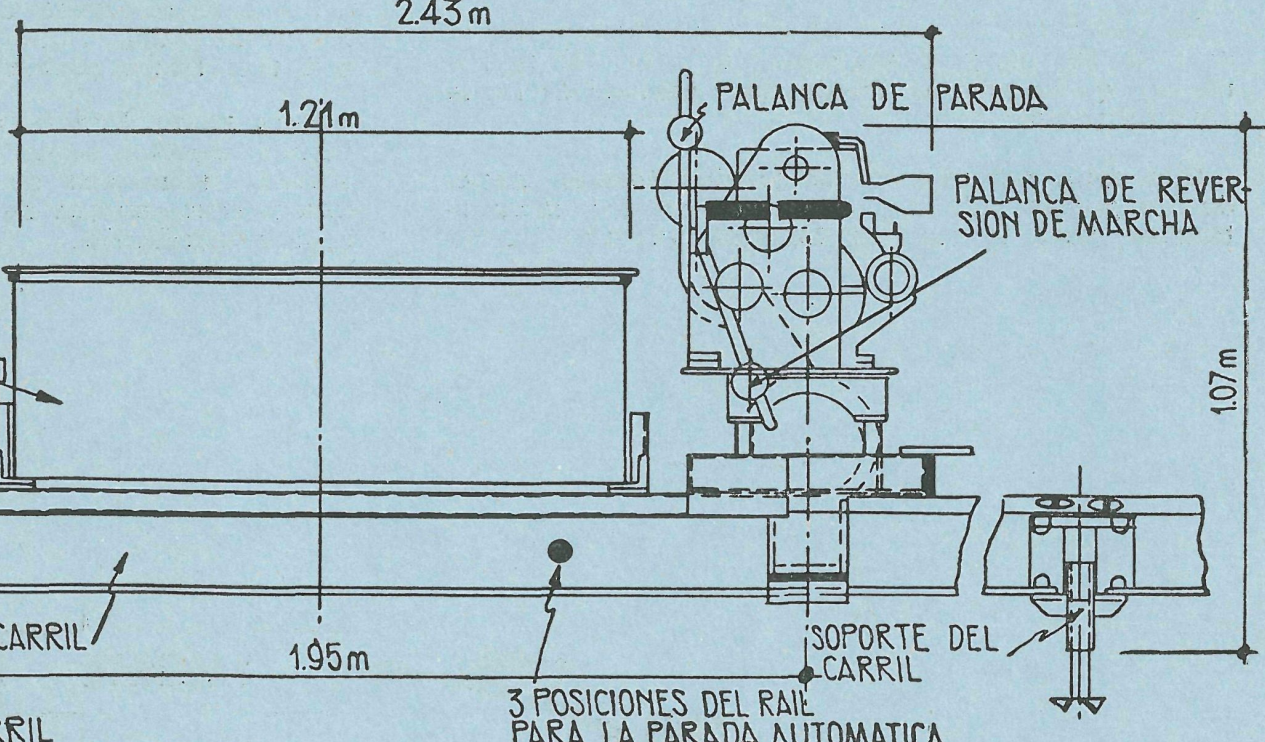

PARA LA PARADA AUTOMATICA

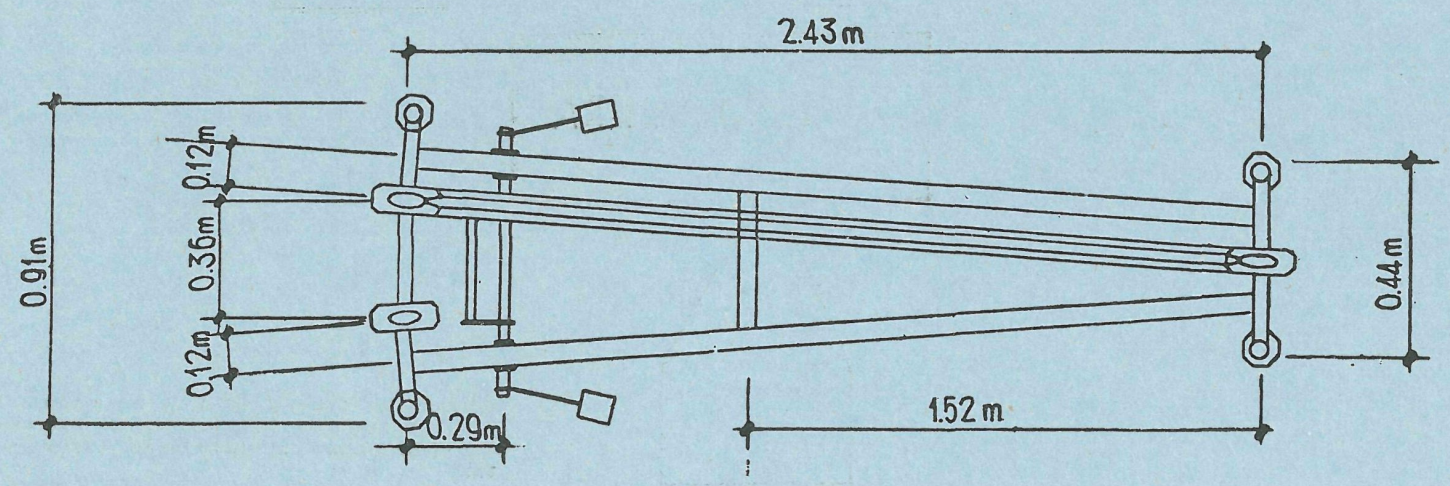




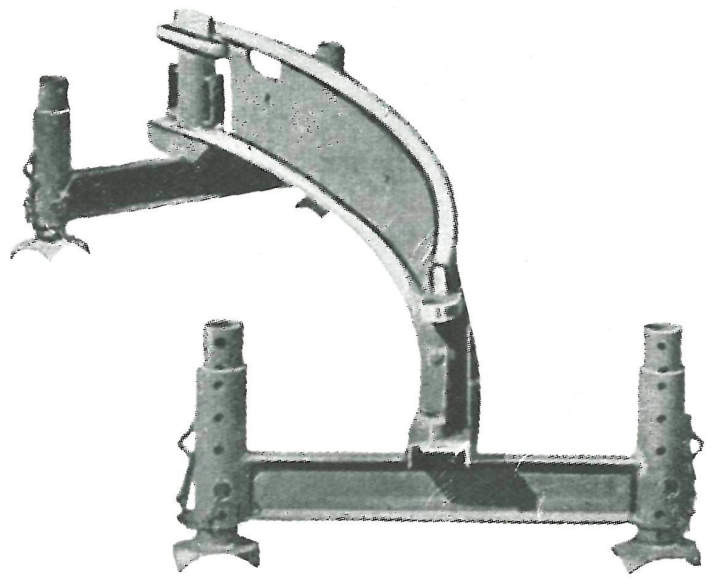

Un trozo de raíl curvo soiore sus soportes.

\section{Aplicaciones prácticas}

Aunque este procedimiento de transporte es aplicable a múltiples empleos y usos, en este trabajo el principal interés se ha encaminado hacia la construcción, donde se puede utilizar para el transporte del hormigón, mortero, ladrillo, escombro, encofrados, etc.

Como en este sistema de transportes se pueden subir rampas de fuerte pendiente, hay casos particulares en que una instalación racional permite suprimir los servicios de grúas aun en los casos de más de una planta.

En los muros de ribera, rellenos de zanjas y transportes de tuberías, el mono-raíl encuentra una aplicación particularmente indicada, como se podrá apreciar en las fotografías adjuntas. En la edificación, esta clase de transporte puede ampliar el radio de acción de grúas y montacargas, pues complementa la acción de estos elementos de elevación, llevando los materiales a los distintos tajos de trabajo.

En la edificación, la instalación del mono-rail no presenta dificultades de mayor importancia, ya que, muros, medianerías, viguetas y hasta la tabiquería, en determinados casos, son excelentes apoyos para la vía de este sistema de transporte.

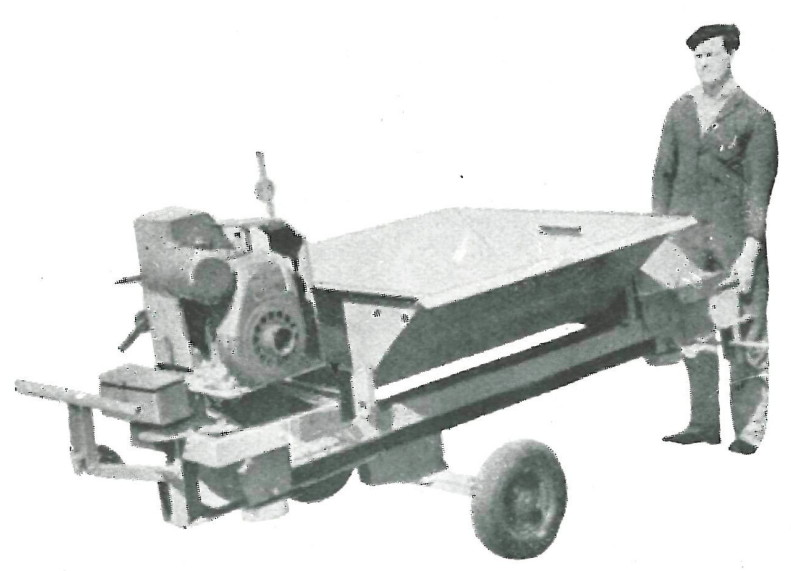

Chasis, provisto de un tren de ruedas neumáticas, utilizado para la carga y descarga de la vagoneta automotor en los traslados o retirada del servicio para ser reparada.
Cuatro ejemplos de disposición de vías para el hormigonado de losas de gran superficie: En a, vía central basculando a ambos lados: eń b, vía lateral a la losa entrando en el tajo por medio de trozos curvos de carril; en e, vía lateral y entrada por medio de trozos cur. vos $y$ rectos; $y$, finalmente, en d se puede apreciar una vía central con derivaciones laterales curvas en los dos sentidos.
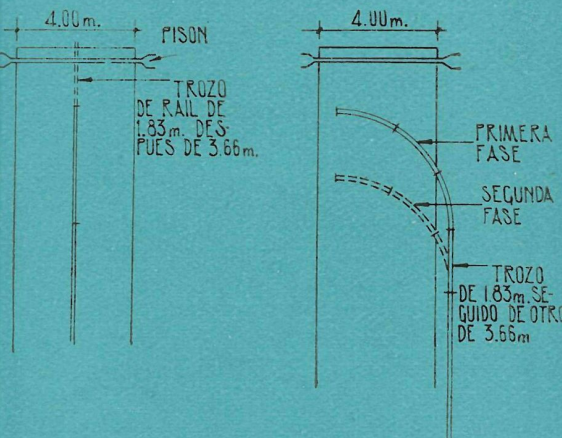

a



C

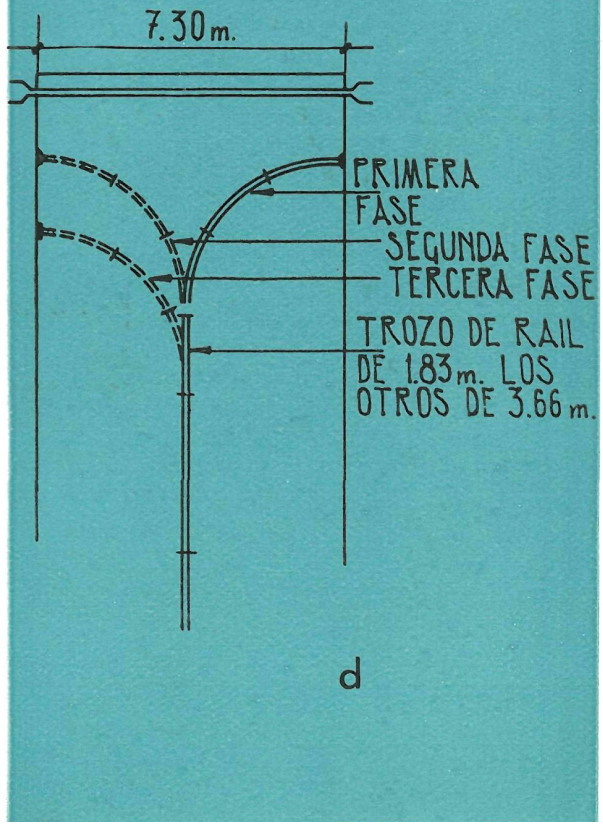




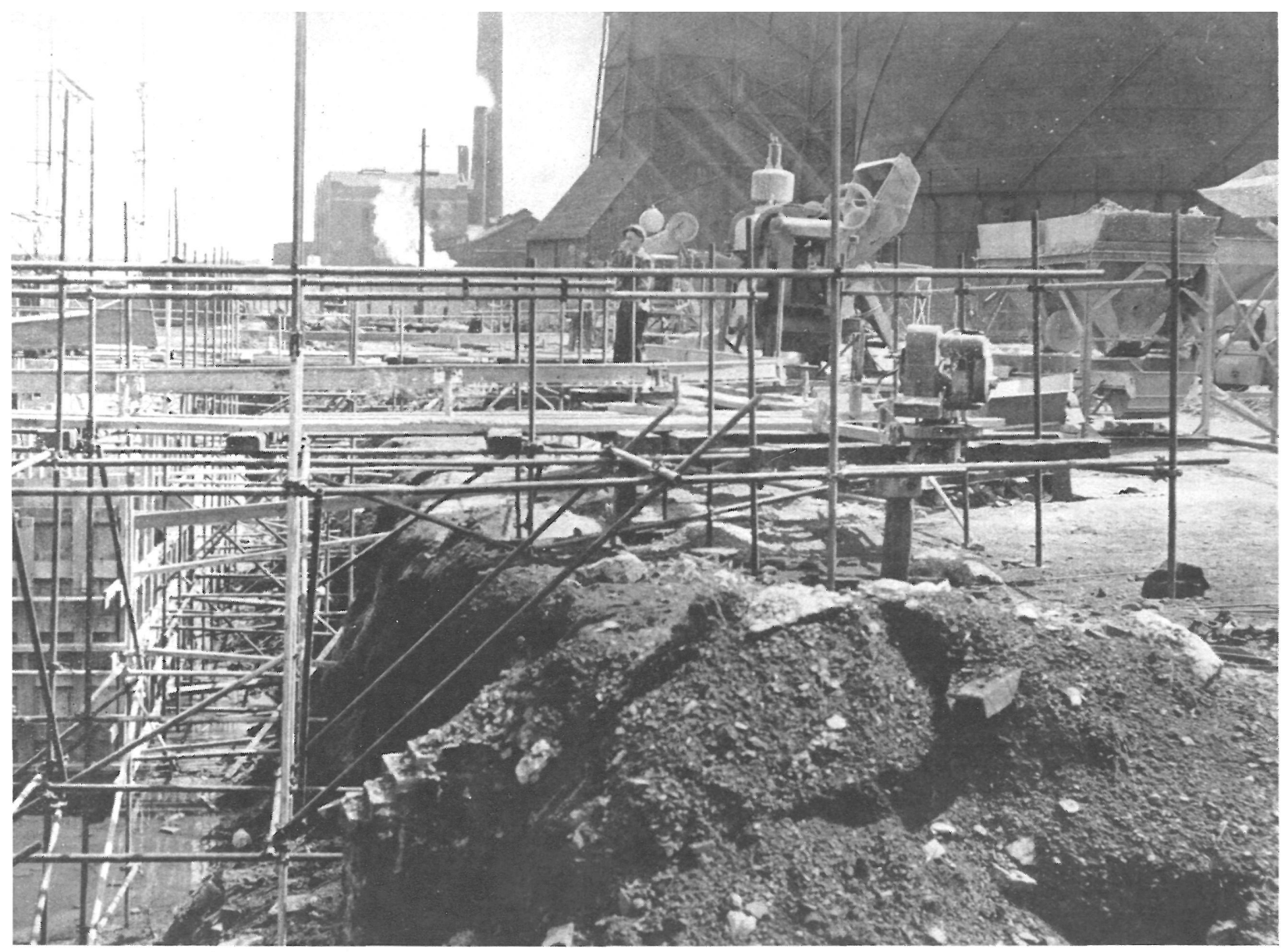

Instalaciones de iransporte por mono rail en la una clasificación de carbón en In da. terra.

Aparentemente no parece de gran utilidad en las obras donde el volumen horario de materiales colocados es de gran consideración; pero, aun en estos casos, hay momentos que, por la particularidad o situación de los tajos, el mono-raíl puede dar un gran rendimiento y eficacia.

Al hormigonar losas armadas o de hormigón en masa, como ocurre en las soleras y forjados, estos sistemas de transporte del hormigón presentan grandes ventajas sobre los procedimientos ordinarios, porque las vías se pueden combinar, cambiar y correr con gran facilidad, permitiendo se pueda descargar en los lugares más apropiados y con maniobras mínimas para extender el hormigón.

\section{Estudio económico de explotación con}

\section{transportes por mono-raí}

Como ejemplo, se ofrecen, a continuación, las siguientes disposiciones de vía y equipos, como sugerencias a los posibles usuarios del transportador mono-raíl. Al estudiar estas disposiciones, hemos tomado como referencia un promedio de producción de 20 coladas de hormigón por hora, que es un rendi-

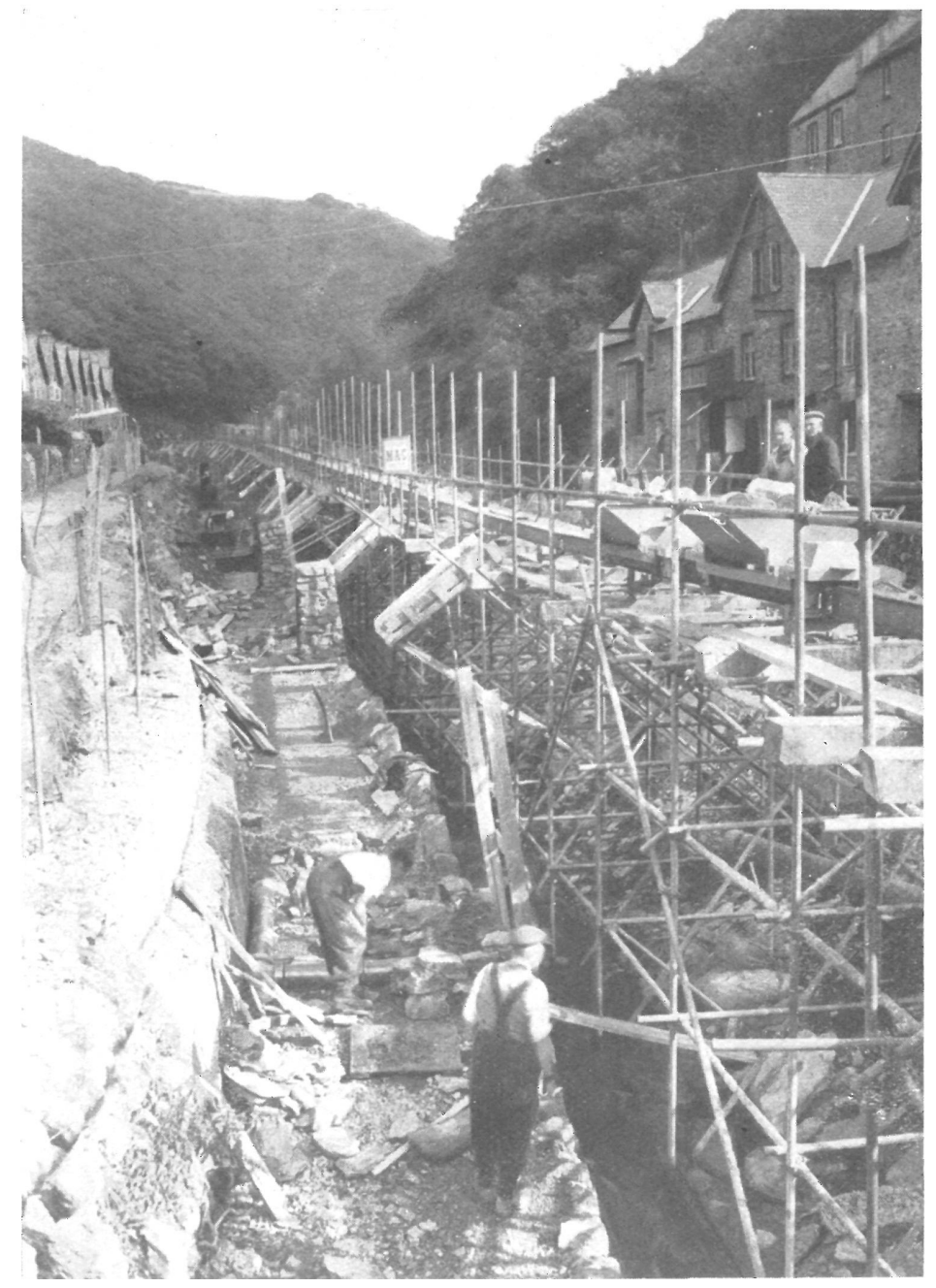

Una aplicación de los transportes por mono-raíl a a construcción de bera. 
miento que se puede obtener fácilmente, y la colocación del raíl es tal, que un aumento de la longitud de arrastre no reduce la media de producción.

EJEMPLO A.-Arrastre máximo, $91 \mathrm{~m}$ (100 yardas). Mezcladora de $10 \mathrm{~N}$. T. Promedio de mezcla, 20 coladas por hora. Producción de hormigón, 5,4 $\mathrm{m}^{3}$ (7 yardas cúbicas) por hora.

Equipo mono-raíl: Un vagón motriz y $91 \mathrm{~m}$ (100 yardas) de raíl y aditamentos. Costo aproximado: $£ 650.0 .0$ (71.500 ptas.).

Este equipo mono-rail es el más sencillo y económico, principalmente a causa de que el tiempo de ciclo del mono-raíl coincide exactamente con el promedio de producción de la mezcladora de hormigón.

Tabla de operaciones:

Descarga de la mezcladora: $1 / 2$ minuto.

Tiempo de viaje:

2. minutos.

Descarga del mono-raíl:

$1 / 2$ minuto.

Costo laboral:

Ninguno.

Amortización:

5,35 ptas. (11,64 d.) por hora.

Gastos de mantenimiento y recorrido:

9,05 ptas. $(19,68$ d.) por hora. Total:

14,40 ptas. (31,32 d.) por hora. Costo de transporte del hormigon por $\mathrm{m}$ :

2,66 ptas.

Por yarda cúbica:

4,47 d. (2,05 ptas.)

Nota.-El costo de amortización ha sido calculado por el método lineal, y será suministrado un estado mostrando cómo se llega a estas cifras, si así nos lo interesan. En las cifras indicadas más arriba, no se tiene en cuenta el ahorro real resultante de los descuentos obtenidos de la Hacienda por la compra de nuevos equipos.

\section{Apartadero en la parte} central del trazado para el cruce de trenes

EJEMPLO B.-Arrastre máximo, $183 \mathrm{~m}$ (200 yardas). Dos mezcladoras de 10 N. T. Promedio de mezcla, 40 coladas por hora. Producción de hormigón, $10,8 \mathrm{~m}^{3}$ (14 yardas cúbicas) por hora.

Los transportes por mono-raíl encuentran un empleo muy práctico en el aprovisionamiento de tuberías en obra. Una aplicación del mono-raíl en la re. paración de un puente.-Los transpor. tes por mono-raíl presentan grandes ventajas en los aprovisionamientos in. teriores en obra, por su fácil adaptación a las máltiples soluciones locales.
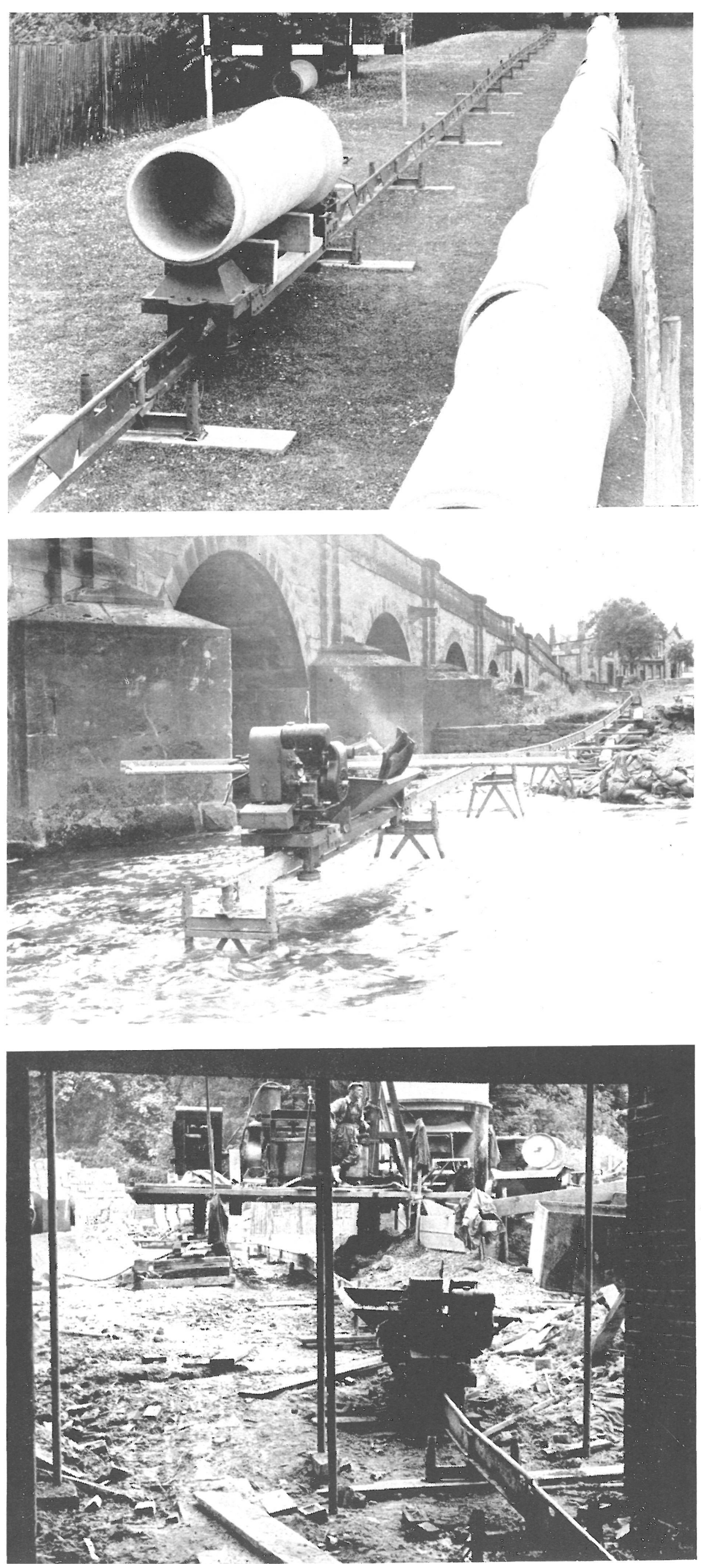

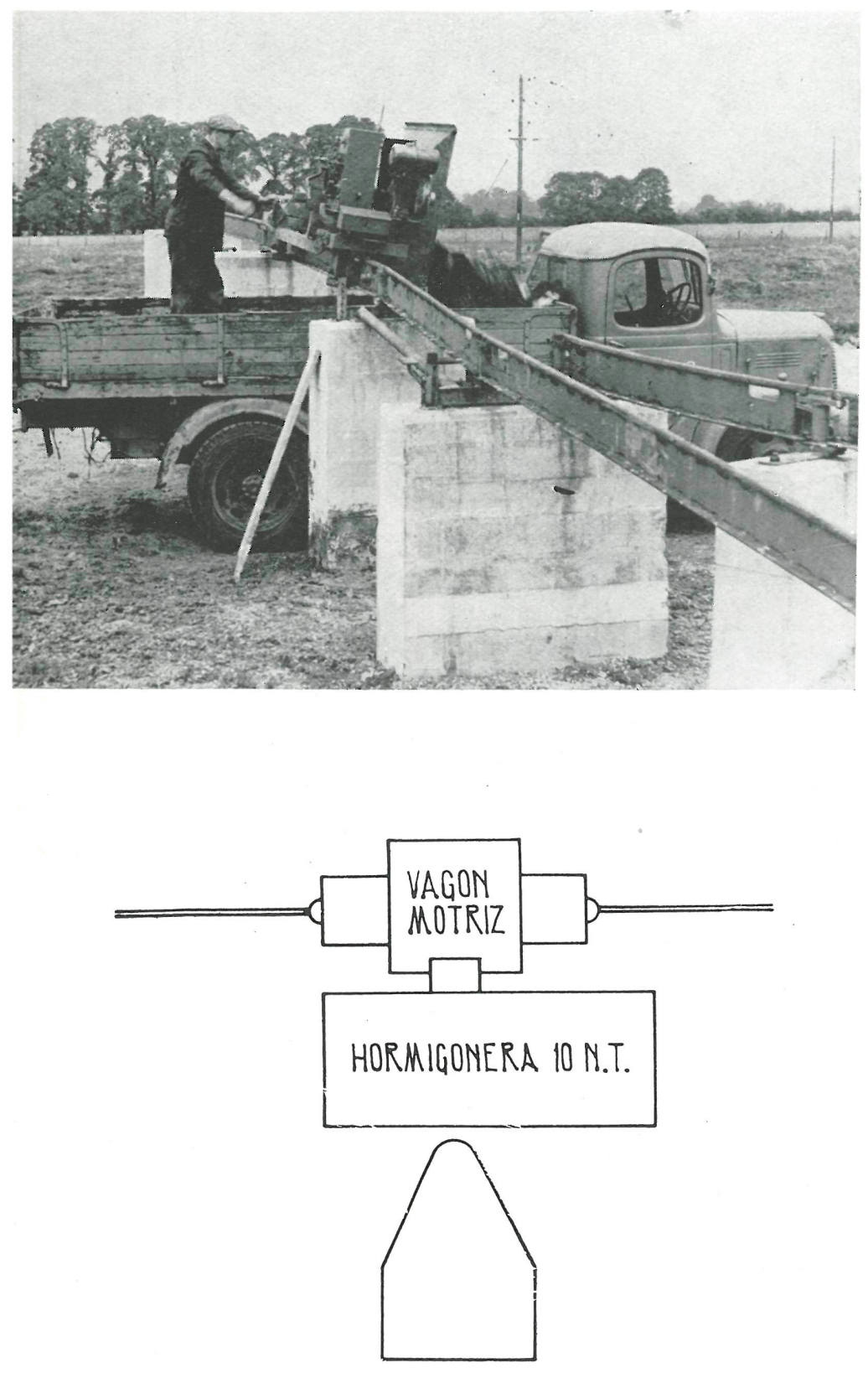
El mono-raíl puede emplearse también, en ocasiones, con
incomparable eficiencia, en el transporte de materiales de relleno, limpieza de escombro y movimiento de tierras.

Las instalaciones del mono-rail pueden ser de carácter provisional, como ocurre en la generalidad de las obras, pero también pueden ser permanentes, como se puede apreciar en la fotografía, donde se emplea este medio de transporte para retirar los materiales sólidos procedentes de las balsas de evaporación de aguas residuales tratadas.

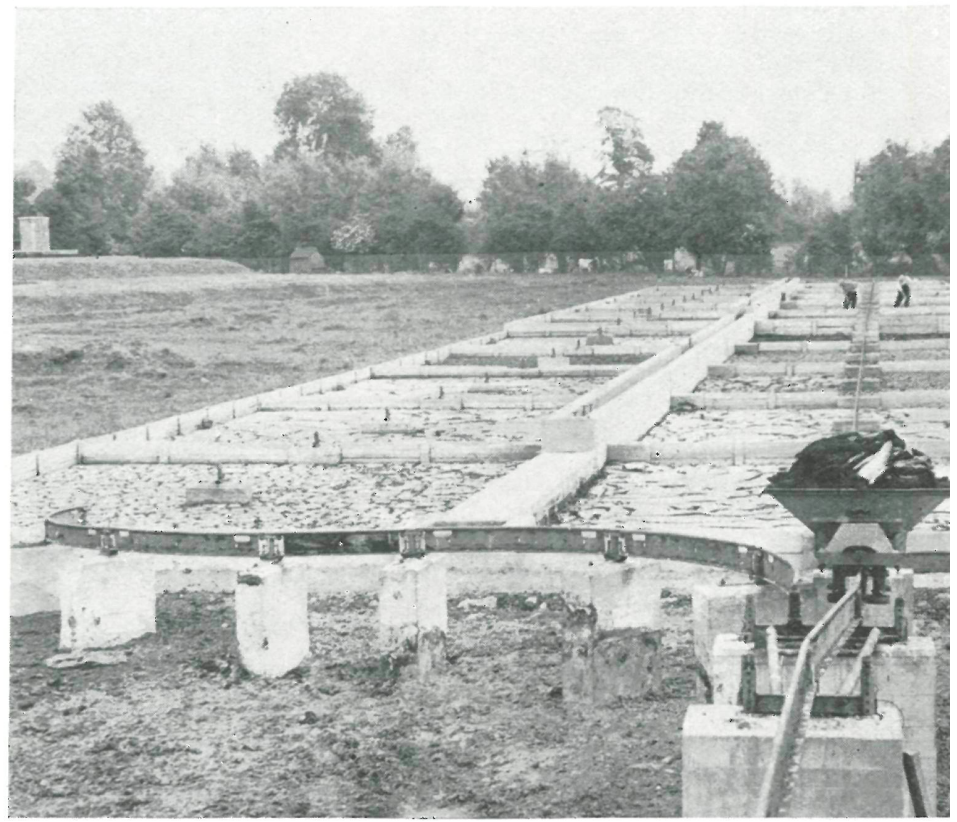

Equipo mono-raíl: Dos vagones motrices, $183 \mathrm{~m}$ (200 yardas) de raíl, dos remolques y aditamentos. Además, equipo para la línea de cambio. Costo aproximado: $£ 1.700 .0 .0$ (187.000 ptas.).

\section{Tabla de operaciones}

Descarga desde dos mezcladoras simultáneamente: $1 / 2$ minuto.

Tiempo de viaje por tren de vagón motriz y remolque: 4 minutos.

Descarga: 1/2 minuto.

Mano de obra (un hombre): 4 s. 0 d. (22 ptas.).

Amortización: 2 s. 7,92 d. (14,64 ptas.) por hora.

Gastos de mantenimiento y recorrido: 2 s. 9,72 d. $(15,47$ ptas.) por hora.

Total: 9 s. 5,64 d. $(52,11$ ptas. $)$ por hora.

Costo del transporte de hormigón por $\mathrm{m}^{3}$ : 4,82 pesetas.

Por yarda cúbica: 3,72 ptas. $(8,12$ d.).

La casa Road Machines Ltd., de Drayton (Inglaterra), ha patentado, en España, este tipo de material y cedido la patente a la casa americana Chain-Belt Co., que está fabricando dicha maquinaria auxiliar de transportes con mucho éxito, bajo la denominación Rex-Railporter, en dicho país.

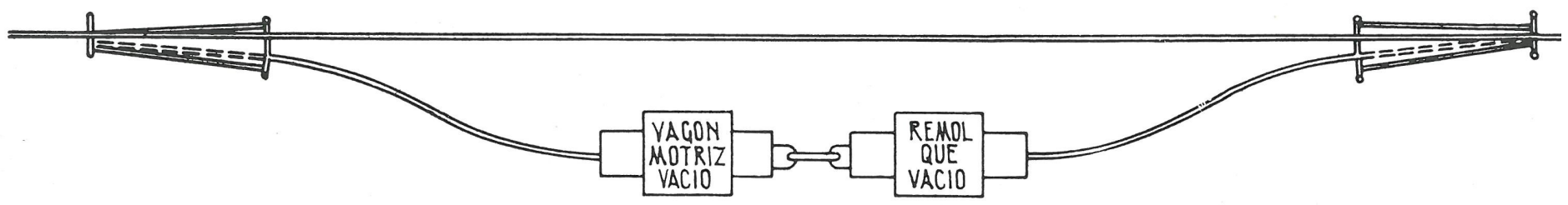

INFORMES DE LA CONSTRUCCION 88 